\title{
Surface Chemical and Textural Modifications of Activated Carbon Prepared from Waste Wood Shavings by Wet Oxidations
}

\author{
A. PAULRAJ ${ }^{*}$ and A. TONY ELIZABETH
}

Post Graduate and Research Department of Chemistry, St. Joseph's College (Autonomous) Tiruchirappalli-620 002, Tamil Nadu, India

paulrajsjc@gmail.com

Received 3 September 2015 / Accepted 5 October 2015

\begin{abstract}
An activated carbon was prepared from waste wood shavings by simple carbonization in a muffle furnace. Wet oxidations of the carbon were carried out with nitric acid, hydrogen peroxide and potassium persulphate. The physicochemical, chemical, FT-IR, $\mathrm{N}_{2}$ adsorption, SEM, TG, DTG and XRD characterizations were done. Though the carbon produced from simple pyrolysis possessed some acidic and basic groups with porous texture, modifications with the chosen reagents improved the surface heterogeneity and porous characteristics. These surface chemical and textural characteristics were presented in this paper.
\end{abstract}

Keywords: Activated carbon, Wet oxidation, Surface groups, Surface area

\section{Introduction}

The term activated carbon is generally used to describe carbon or charcoal whose adsorptive capacities have been increased by man-made processes ${ }^{1}$. They contain, in general, carbon as the major component and small amounts of some hetero atoms like oxygen and nitrogen depending upon their origin or the nature of process by which they are prepared. They can be distinguished by their surface morphology, surface area and most importantly by their adsorptive properties with different solutes ${ }^{1}$. Of all the treatment methods available for the removal of dissolved contaminants, adsorption - especially onto low-cost adsorbents like activated carbon - is the most preferred one because it is economic and is also a green purification technique.

The cost of this process can further be reduced by looking for a cheap, locally available carbonaceous material as the adsorbent which can be an agricultural waste or a wood industry waste. Tones of hard carbon masses of varied sizes are produced as waste byproducts in wood industry. Numerous attempts have been made by researchers to identify and utilize these waste materials for activated carbon production ${ }^{2-4}$. They include cellulosic biomasses like wheat and rice straw, nut shells, fruit pits, peels, corn cobs, bagasse, oilcakes, leaves, barks, saw dusts, wood wastes and others. The adsorptions of organic 
molecules like dyes and heavy metals by these carbons have also been reviewed ${ }^{5,6}$. Even though simple carbonization of these materials at controlled conditions yield carbons of considerable porosity and hydrophobicity which can remove non-polar organics, they do lack surface heterogeneity that is key for the attraction of polar organics like phenols and inorganic ions $\mathrm{s}^{7-10}$. Surface heterogeneity on carbons can be increased by wet oxidations with nitric acid, sulphuric acid, hydrochloric acid, phosphoric acid, hydrogen peroxide, ammonium persulphate and others ${ }^{11-15}$.

The objective of the present work is to convert waste wood shavings procured from a local furniture workshop by carbonization and to study the changes on the surface physical and chemical characteristics on treatment with concentrated nitric acid, hydrogen peroxide and potassium persulphate. The changes that took place can be assessed by nitrogen adsorption, scanning electron microscopic study, XRD analysis, thermal analysis, FT-IR spectral analysis, Boehm and mass titrations in addition to the standard testing methods for physicochemical characterizations.

\section{Experimental}

Waste wood shavings of teak wood (Tectona grandis) for the preparation of activated carbon were collected from a local furniture workshop. The shavings were thoroughly washed with water, dried in air and carbonized directly in a muffle furnace at a temperature of about $500{ }^{\circ} \mathrm{C}$ for 30 minutes. The resulting black product was ground and sieved and the portion retained between 150 and $250 \mu \mathrm{m}$ sieves was repeatedly washed with double distilled water, dried overnight at $120 \pm 5^{\circ} \mathrm{C}$, cooled in a desiccator and stored. This carbon was named as $\mathrm{C} 1$.

Three other carbons, namely, $\mathrm{C} 2, \mathrm{C} 3$ and $\mathrm{C} 4$ were prepared from $\mathrm{C} 1$ by wet oxidation methods using concentrated nitric acid $(16 \mathrm{M})$, hydrogen peroxide $(30 \%)$ and potassium persulpahte (saturated solution in $1 \mathrm{M} \mathrm{H}_{2} \mathrm{SO}_{4}$ ), respectively. Briefly, about $5 \mathrm{~g}$ of C1 was mixed with $50 \mathrm{~mL}$ of the agents for a period of ten hours at room temperature. The carbon masses were then separated and excess reagents were removed by washing in a Soxhlet apparatus.

\section{Characterization of the adsorbents}

Physico-chemical characteristics were determined following standard methods ${ }^{16}$, The fixed carbon content is calculated from the following equation ${ }^{17}$ :

$$
\text { Fixed carbon }=100-[\% \text { moisture }+ \text { volatile matter }+\% \text { ash }]
$$

Cation-exchange capacity (CEC) determinations ${ }^{18}$, Boehm titrations ${ }^{19,20}$ and mass titrations ${ }^{21}$ were performed following reported procedures. FT-IR spectra were recorded in a Perkin Elmer FT-IR spectrophotometer RS1 in the region 4000-400 $\mathrm{cm}^{-1}$. The morphologies and sizes of the samples were examined using field emission scanning electron microscopy ((FE-SEM) (JSM-6701F, JEOL Japan INC) with an accelerating voltage $30 \mathrm{kV}$ and filament current of $20 \mathrm{~mA}$ for 45 seconds. EDX was performed with Oxford instrument attached with SEM. Brunauer-Emmett-Teller (BET) specific surface areas of the carbons and pore size distributions were obtained by nitrogen adsorption on an Autosorb-1 (Quantachrome Instruments, Boynton Beach, FL) nitrogen adsorption apparatus. Thermal behaviors were analyzed by means of an EXSTAR6200 thermal analyzer at a heating rate of $10{ }^{\circ} \mathrm{C} / \mathrm{min}$, from room temperature to $1000{ }^{\circ} \mathrm{C}$ in air. Powder X-ray diffraction (PXRD) patterns were measured using a XRD-Bruker D8 Advance XRD with $\mathrm{Cu} \mathrm{K} \alpha$ radiation $(\lambda=1.54050 \AA)$ operated in the $2 \theta$ range from $10^{\circ}$ to $50^{\circ}$. 


\section{Results and Discussion}

\section{Physicochemical characterizations}

Moisture content dilutes the carbon and therefore necessitates the use of additional weight of carbon to provide the required weight. Ash content generally gives an idea about inorganic constituents associated with carbon. Density may be regarded as the measure of activity of carbon. When the carbon is in contact with water, leaching of impurities from carbon should not be significant, so tests pertaining to acid soluble and water-soluble matter assume importance. The volatile matter content may be used as a relative measure of the extent of carbonization and the extent of loading of volatile matter on an activated carbon that has been used in an adsorption process. These properties for the carbons prepared were listed in Table 1.

Table 1. Physicochemical characteristics of the activated carbons

\begin{tabular}{lllll}
\hline Characteristics & \multicolumn{1}{c}{$\mathrm{C} 1$} & \multicolumn{1}{c}{$\mathrm{C} 2$} & \multicolumn{1}{c}{$\mathrm{C} 3$} & $\mathrm{C} 4$ \\
\hline Proximate analysis, \% & & & & \\
Moisture & 1.87 & 2.24 & 2.57 & 2.62 \\
Ash & 13.54 & 11.44 & 12.18 & 12.20 \\
Volatile matter & 2.56 & 8.51 & 5.81 & 3.45 \\
$\quad$ Fixed carbon & 82.03 & 77.81 & 79.44 & 81.73 \\
Particle size, $\mu \mathrm{m}$ & $150-250$ & $150-250$ & $150-250$ & $150-250$ \\
Apparent density, g/mL & 0.75 & 0.71 & 0.64 & 0.68 \\
Dry apparent density, g/mL & 0.71 & 0.68 & 0.59 & 0.58 \\
Water solubles, \% & 2.85 & 2.12 & 2.45 & 2.84 \\
Acid- extractable content, \% & 9.45 & 6.52 & 6.84 & 6.91 \\
pH & 8.68 & 4.46 & 4.86 & 5.11 \\
\hline
\end{tabular}

\section{Chemical characterization results}

Surface heterogeneity of carbons is mainly due to oxygen atoms on the surface. A heterogeneous surface is loaded with oxygen atoms in the form of chemical groupings like, carbonyl, carboxylic, lactonic, phenolic which are acidic and chromene, quinone and pyrone groups that are basic ${ }^{22}$. Oxidizing agents like those used in our study, are predicted to increase the density of acidic groups and indeed this expectation is realized and the results are shown in Table 2.

Table 2. Chemical properties of activated carbons

\begin{tabular}{lcccc}
\hline \multicolumn{1}{c}{ Chemical property } & $\mathrm{C} 1$ & $\mathrm{C} 2$ & $\mathrm{C} 3$ & $\mathrm{C} 4$ \\
\hline Surface groups, mequiv/g & & & & \\
Carboxyl & 0.043 & 0.815 & 0.668 & 0.389 \\
Phenolic & 0.197 & 0.921 & 0.874 & 0.445 \\
Lactonic & 0.183 & 0.658 & 0.342 & 0.283 \\
Acidic groups & 0.423 & 2.394 & 1.884 & 1.117 \\
Basic groups & 0.682 & 0.158 & 0.177 & 0.424 \\
Total groups & 1.105 & 2.552 & 2.061 & 1.541 \\
$\mathrm{CEC}\left(\times 10^{-4} \mathrm{~mol} / \mathrm{g}\right)$ & 1.75 & 5.50 & 4.75 & 4.50 \\
$\mathrm{pH}$ & 8.57 & 4.21 & 4.51 & 5.02 \\
\hline
\end{tabular}

That the parent carbon $\mathrm{C} 1$, is fundamentally basic is revealed by the relatively low number of acidic groups and more number of basic groups. It is also supported by the CEC and the $\mathrm{pH}_{\mathrm{ZPC}}$ values. Oxidation results in significant increase in the number of acid groups 
which may be due to the oxidation of carbon atoms held at the periphery; and decreases the number of basic groups ${ }^{14}$ which may be due to conversion of a group like chromene into a carboxyl or other by the oxidizing agent. It is evident from Table 2 that among the reagents, nitric acid produced more number of carboxyl, phenolic and lactonic groups. Similar types of observations have also been reported earlier ${ }^{23}$.

\section{FT-IR spectra}

The FT-IR spectra (Figure 1) reveal that the carbons are loaded with plenty of surface groups $^{22,24}$. Broad peaks at about $3400 \mathrm{~cm}^{-1}$ are indications of the presence of hydroxyl groups of phenols and carboxylic acids held in close proximity on the surfaces of the carbons. The weak bands at $2850 \mathrm{~cm}^{-1}$ and $2920 \mathrm{~cm}^{-1}$ are due to aromatic $(\mathrm{C}-\mathrm{H})$ stretchings. The peaks close to $1600 \mathrm{~cm}^{-1}$ are due to the carbonyls of carboxylic and lactonic groups. The graphitic $(\mathrm{C}=\mathrm{C})$ stretching vibrations may also be responsible for these bands. Bands at $1400 \mathrm{~cm}^{-1}$ are due the $(\mathrm{C}-\mathrm{O})$ stretching vibrations of alcohols, esters, lactones and other ether linkages. The peak intensities observed for the acidic groups (Figure 1) suggest that among the modifications $\mathrm{C} 2$ is the richest and $\mathrm{C} 4$ is the poorest in the possession of these groups. These results are also consistent with the Boehm titration results (Table 2).

ACIC
St.Joseph's College ( Autonomous)
Trichy-2

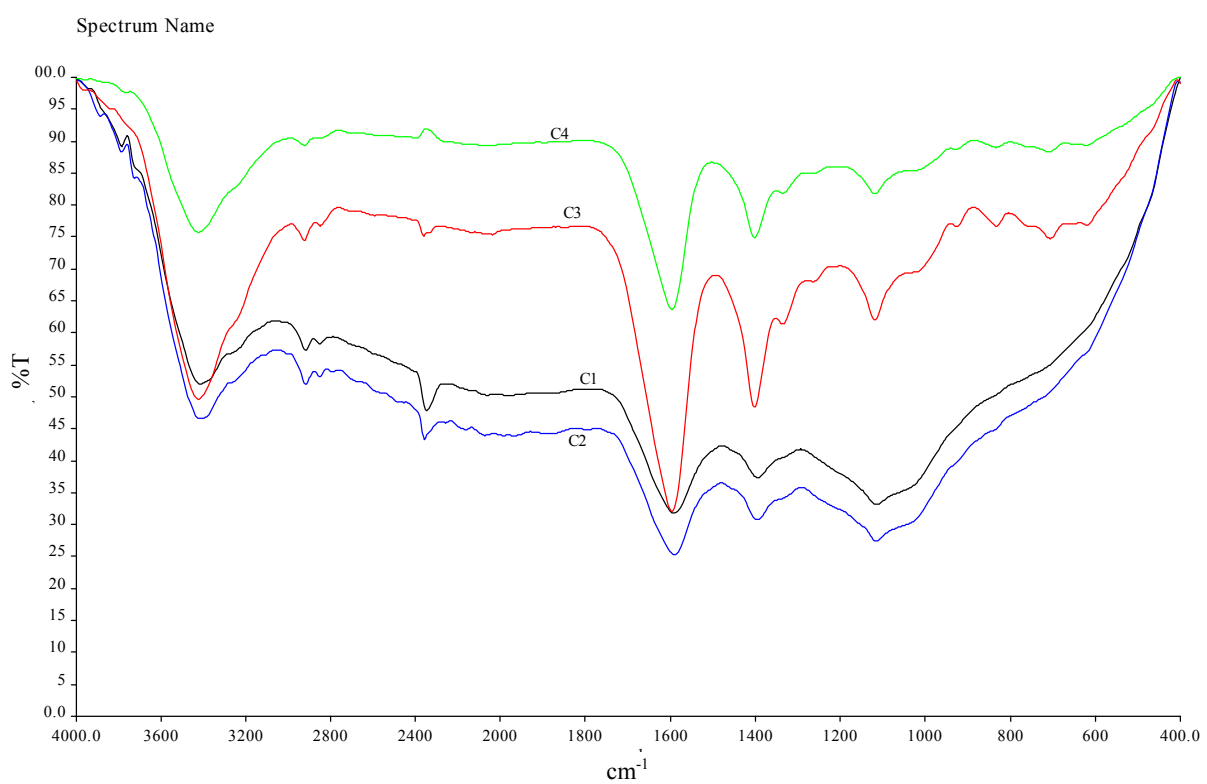

Figure 1. FT-IR spectra of the activated carbons

\section{Surface area analysis and pore size distribution by nitrogen adsorption}

The nitrogen adsorption isotherms of the carbons were all found to be of Type $\mathrm{I}^{25}$ and are shown in Figure 2. Sharp increase of $\mathrm{N}_{2}$ adsorption at $\mathrm{P} / \mathrm{P}_{0}$ less than 0.1 are indications of highly microporous nature of the adsorbents. BET surface areas of the carbons increased dramatically in the case of $\mathrm{C} 3$ and especially $\mathrm{C} 4$. But with $\mathrm{C} 2$ there is only a very little increase in surface area and that too is realized as $\mathrm{P} / \mathrm{P}_{0}$ values higher than about 0.4 . The surface area, pore volumes and pore sizes deduced from nitrogen adsorption are presented in Table 3. 


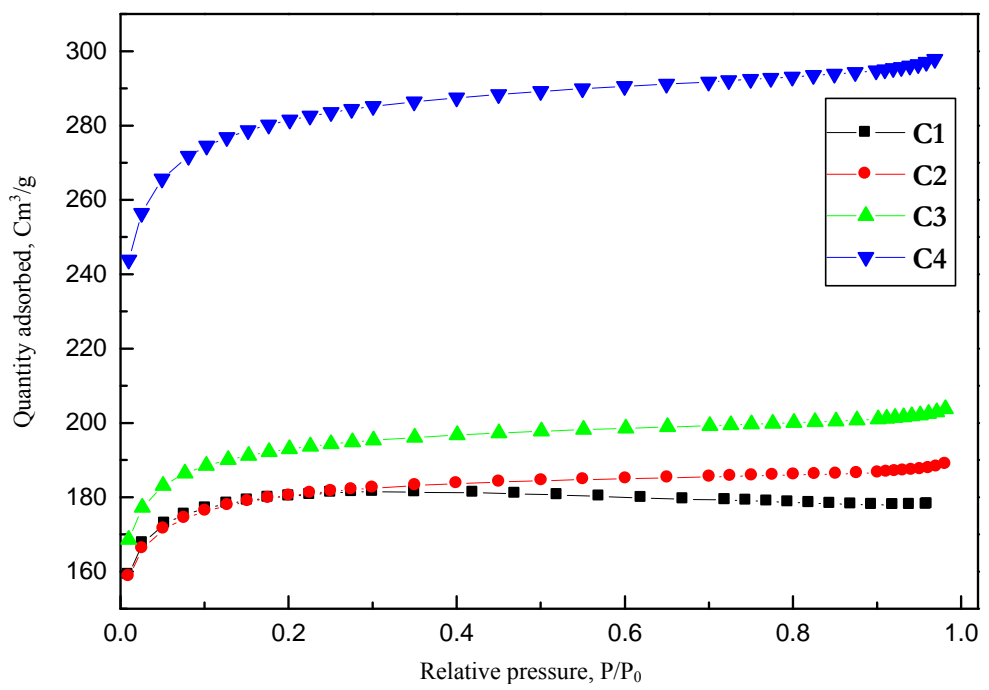

Figure 2. $\mathrm{N}_{2}$ adsorption isotherms of activated carbons

Table 3. Physical properties of activated carbons deduced from $\mathrm{N}_{2}$ adsorption

\begin{tabular}{lrrrr}
\hline \multicolumn{1}{c}{ Physical property } & \multicolumn{1}{c}{$\mathrm{C} 1$} & \multicolumn{1}{c}{$\mathrm{C} 2$} & \multicolumn{1}{c}{$\mathrm{C} 3$} & \multicolumn{1}{c}{$\mathrm{C} 4$} \\
\hline Single point surface area at $\mathrm{P} / \mathrm{P}_{0}=0.3005, \mathrm{~m}^{2} / \mathrm{g}$ & 552.4118 & 555.7582 & 594.3640 & 868.3045 \\
BET surface area, $\mathrm{m}^{2} / \mathrm{g}$ & 544.0511 & 548.1014 & 586.6531 & 856.9818 \\
t-Plot Micropore $\mathrm{area}, \mathrm{m}^{2} / \mathrm{g}$ & 490.4677 & 472.9118 & 503.4626 & 713.2577 \\
t-Plot External Surface Area, $\mathrm{m}^{2} / \mathrm{g}$ & 53.5834 & 75.1896 & 83.1906 & 143.7241 \\
Single point adsorption volume of pores, $\mathrm{cm}^{3} / \mathrm{g}$ & 0.2818 & 0.2968 & 0.3216 & 0.4709 \\
t-Plot micropore volume, $\mathrm{cm}^{3} / \mathrm{g}$ & 0.2550 & 0.2457 & 0.2616 & 0.3716 \\
Adsorption average pore $\mathrm{width}$ & 2.0718 & 2.1657 & 2.1930 & 2.1981 \\
(4V/A by BET), nm & 0.2028 & 0.2158 & 0.2444 & 0.3593 \\
Volume in pores $<1.483 \mathrm{~nm}, \mathrm{~cm}^{3} / \mathrm{g}$ & 0.2247 & 0.2397 & 0.2671 & 0.3851 \\
Total Volume in Pores $\leq 185.804 \mathrm{~nm}, \mathrm{~cm}^{3} / \mathrm{g}$ & 0.0000 & 0.0000 & 0.0000 & 1.8270 \\
Area in Pores $>185.804 \mathrm{~nm}, \mathrm{~m}^{2} / \mathrm{g}$ & 23.8070 & 17.1950 & 12.6350 & 15.7770 \\
Total Area in Pores $\geq 1.483 \mathrm{~nm}, \mathrm{~m}^{2} / \mathrm{g}$ & &
\end{tabular}

It is seen that there is an increase in the total surface area of the carbons in the order, $\mathrm{C} 1$ $<\mathrm{C} 2<\mathrm{C} 3<\mathrm{C} 4$. This is expected because the parent carbon is actually a wood char; tarry residues and other volatile impurities produced during the carbonization process might have been trapped into the pores and making them unavailable and unseen. It is for this reason any carbonized material is activated physically or chemically. Oxidants react with the tarry residues trapped in pores and expose them, which help the unveiling of the original porosity. Creation of new pores by them is also possible. Thus the oxidized versions of $\mathrm{C} 1$ are predicted to have higher surface area and pore volumes. Many works have been reported in the literature where increase in surface area is realized when carbonized biomasses ${ }^{26-28}$ and commercial carbons ${ }^{29,30}$ were activated.

Of the three modifications, the surface area and the porosity increased in the following order: nitric acid < hydrogen peroxide $<$ potassium persulphate. The lowest pore development is seen in the case of $\mathrm{C} 2$ and this could be due to the strong oxidizing behaviour 
and blocking of pores by carboxyl and lactone groups which prevent the entry of $\mathrm{N}_{2}$ molecules ${ }^{31}$. Even though, oxidation treatments increased porosity in $\mathrm{C1}$, average pore widths (Table 3 ) of the carbons have similar values and only the volume of pores seems to be increased.

\section{Scanning electron microscopic studies}

The scanning electron microscopic images along with the EDX spectra are provided in Figure 3. The SEM images reveal that minute micropore development on going from $\mathrm{C} 1$ to $\mathrm{C} 4$ which is highlighted in the $\mathrm{N}_{2}$ adsorption isotherm studies. Further, the EDX spectra reveal the oxygen contents of the samples. They were found to be (in percentage) 15.16, 20.27, 21.25 and 16.21, for C1, C2, C3 and C4, respectively. Increased oxygen contents in the form of surface oxygen complexes as revealed by chemical characterizations is in agreement with these EDX results.

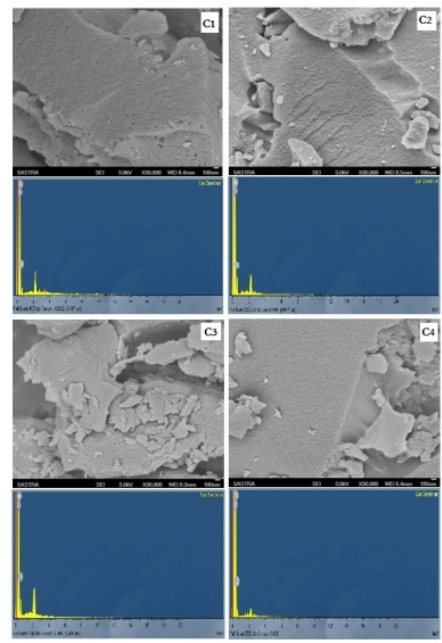

Figure 3. SEM images of activated carbons along with their EDX spectra

\section{Thermal analysis}

The TG and DTG curves for the carbons are shown in Figures 4 and 5. The curves are characteristic of a carbonaceous precursor and the residual weight percentages are found to be $88.10(\mathrm{C} 1), 77.62(\mathrm{C} 2), 83.02(\mathrm{C} 3)$ and $83.36(\mathrm{C} 4)$. The weight losses recorded for the temperature range $0-1000{ }^{\circ} \mathrm{C}$ can be divided into the following phases. The first phase that spans from $0{ }^{\circ} \mathrm{C}$ to about $100{ }^{\circ} \mathrm{C}$ is due to the loss of adsorbed water molecules. In DTG it appears as a small endothermic peak. The second phase, which spans from $200{ }^{\circ} \mathrm{C}$ to $600{ }^{\circ} \mathrm{C}$, is due to the loss of surface oxygen groups in the form of $\mathrm{CO}_{2}$ from the carbons though $\mathrm{CO}$ emissions contribute partly ${ }^{32,33}$. The final phase which starts at $600{ }^{\circ} \mathrm{C}$ could be due to the loss of CO molecules from tightly bound surface oxygen groups ${ }^{34}$.

\section{$X$-ray diffraction studies}

All the carbons have broad peaks at $2 \theta$ values around $14^{\circ}, 27^{\circ}$ and $43.5^{\circ}$ (Figure 6). These broad peaks are characteristics of highly amorphous substances and show that there is no significant change in the surface crystalline nature of $\mathrm{C} 1$ on modifications. Peaks at $\approx 14^{\circ}$ are obtained for some carbons prepared plant biomasses ${ }^{35}$ and could be due the $(1 \overline{1} 0)$ crystallographic plane of residual cellulosic materials ${ }^{36}$. The peaks at $27^{\circ}$ and $43.5^{\circ}$ could be due to the disordered $\left(\begin{array}{lll}0 & 0 & 2\end{array}\right)$ and $\left(\begin{array}{ll}1 & 0\end{array}\right)$ graphitic reflections ${ }^{37}$. 


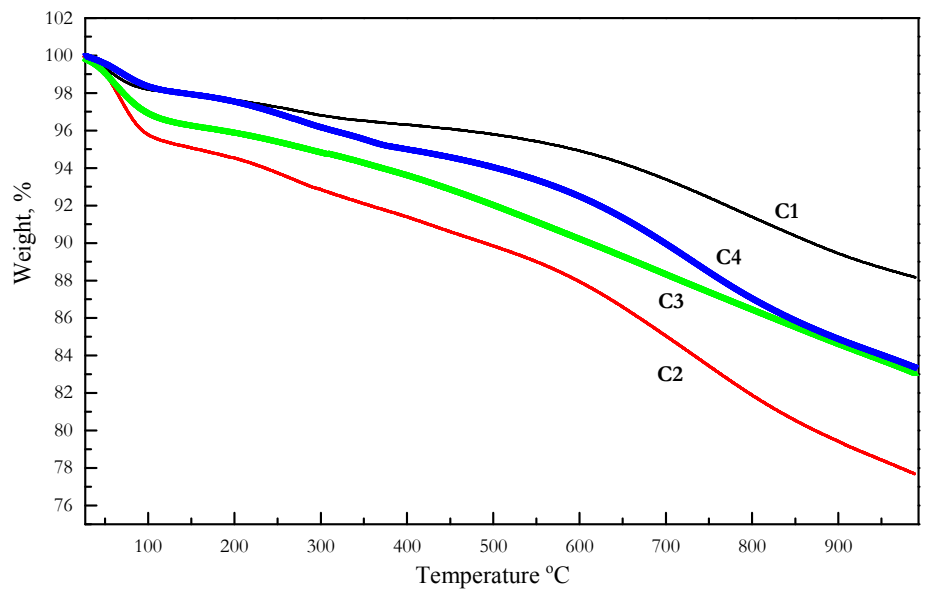

Figure 4. TG curves for activated carbons

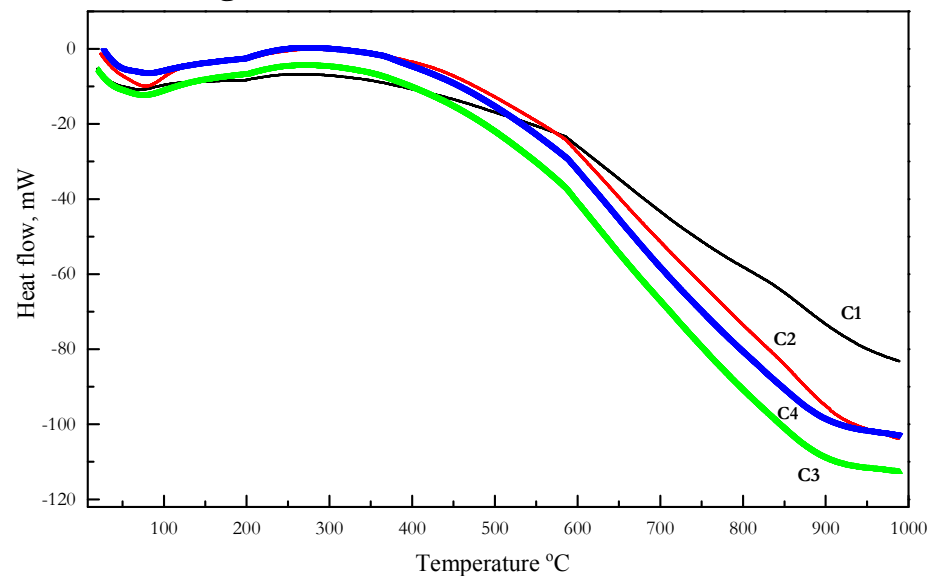

Figure 5. DTG curves for activated carbons

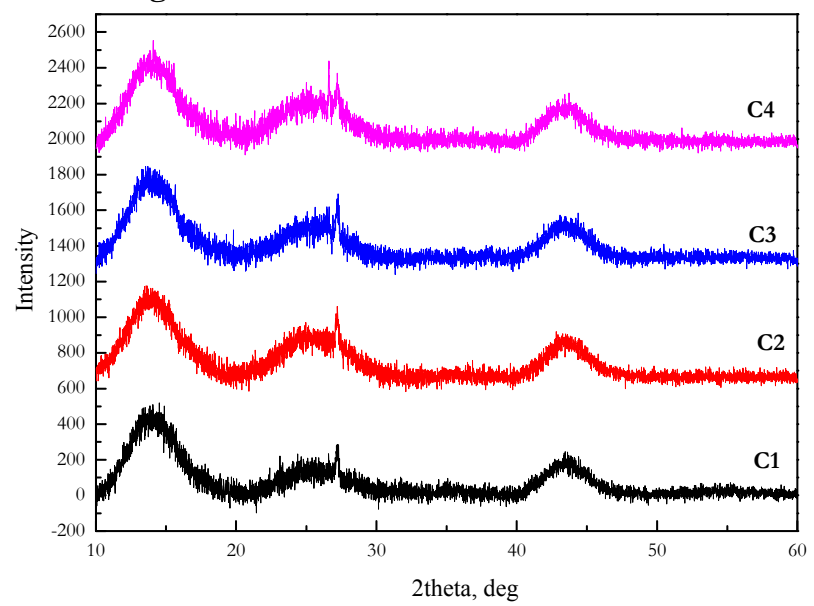

Figure 6. XRD patterns of activated carbons 


\section{Conclusion}

The study reported in this work pertains to the production of activated carbon from waste wood shavings and modifications of the resulting carbon with nitric acid, hydrogen peroxide and potassium persulphate. The carbon produced was found to be porous and the porosity increased by the activation procedures. Modifications of waste wood carbon increased the amounts of surface oxygen complexes like phenolic, lactonic and carboxyl but the amounts of basic groups were reduced. Improved surface area and porous characteristics were supported by $\mathrm{N}_{2}$ adsorption and SEM analyses.

\section{References}

1. Hassler J W, Activated Carbon; Chemical Publishing Company Inc: New York, 1963.

2. Ioannidou O and Zabaniotou A, Renew Sust Energ Rev., 2007, 11(9), 1966-2005; DOI:10.1016/j.rser.2006.03.013

3. Dias J M, Alvim-Ferraz M C M, Almeida M F, Rivera-Utrilla J and Sanchez-Polo M, J Environ Manage., 2007, 85(4), 833-846; DOI:10.1016/j.jenvman.2007.07.031

4. Nor N M, Chung L L, Teong L K and Mohamed A R, J Environ Chem Eng., 2013, 1(4), 658-666; DOI:10.1016/j.jece.2013.09.017

5. Demirbas A, J Hazard Mater., 2009, 167(1-3), 1-9; DOI10.1016/j.jhazmat.2008.12.114

6. Demirbas A, J Hazard Mater., 2008, 157(2-3), 220-229; DOI:10.1016/j.jhazmat.2008.01.024

7. Abu-Daabes M A and Pinto N G, Sep Sci Technol., 2004, 39(13), 2997-3009

8. Bautista-Toledo I, Rivera-Utrilla J, Ferro-Garcia M A and Moreno-Castilla C, Carbon, 1994, 32(1), 93-100; DOI:10.1016/0008-6223(94)90013-2

9. Solar J M, Leon C A, Osseo-Asare K and Radovic L R, Carbon, 1990, 28(2/3), 369-375; DOI:10.1016/0008-6223(90)90010-V

10. Sato S, Yoshihara K, Moriyama K, Machida M and Tatsumoto H, Appl Surf Sci., 2007, 253(2), 554-559; DOI:10.1016/j.apsusc.2005.12.119

11. Noh J S and Schwarz J A, Carbon., 1990, 28(5), 675-682; DOI:10.1016/00086223(90)90069-B

12. Wang S and Zhu Z H, Dyes Pigments., 2007, 75(2), 306-314; DOI:10.1016/j.dyepig.2006.06.005

13. Castro-Muniz A, Suarez-Garcia R, Martinez-Alonso A and Tascon J M D, J Colloid Interf Sci., 2011, 361(1), 307-315; DOI:10.1016/j.jcis.2011.05.064

14. Moreno-Castilla C, Lopez-Ramon M V and Carrasco-Marin F, Carbon., 2000, 38(14),1995-2001; DOI:10.1016/S0008-6223(00)00048-8

15. Pradhan B K, Sandle N K, Carbon., 1999, 37(8), 1323-1332; DOI:10.1016/S00086223(98)00328-5

16. Annual Book of ASTM Standards; Volume 15.01, Refractories; Activated Carbon; Advanced Ceramics, 2001.

17. Kuriakose J C and Rajaram J, Chemistry in Engineering and Technology; Volume 2, Tata McGraw-Hill Publishing Company Limited; New Delhi, 1996, 346

18. Devranche M, Lacor S, Bordas F and Jean-Claude Bollinger, J Chem Educ., 2003, 80(1), 76-78; DOI:10.1021/ed080p76

19. Salame I I and Bandosz T J, J Colloid Interf Sci., 1999, 210(2), 367-374; DOI:10.1006/jcis.1998.5918

20. Adib F, Bagreev A and Bandosz T J, J Colloid Interf Sci., 1999, 214(2), 407-415; DOI:10.1006/jcis.1999.6200 
21. Tajana Preocanin and Nikola Kallay, Croat Chem Acta, 1998, 71(4), 1117-1125.

22. Bandosz $\mathrm{T} \mathbf{J}$ (Ed.), in Activated Carbon Surfaces in Environmental Remediation, Interface Science and Technology; Volume 7, Academic Press: New York, 2006

23. Edwin Vasu A, J Chem., 2008, 5(4), 814-819; DOI:10.1155/2008/610503

24. Marsh $\mathrm{H}$ and Rodriguez-Reinoso F, Activated Carbon, Elsevier Science and Technology Books; New York, 2006.

25. Rouquerol J, Avnir D, Fairbridge C W, Everett D H, Pernicone H N, Ramsay J, Sing K S and Unger K K, Pure Appl Chem., 1994, 66(8), 1739-1758

26. Williams P T and Reed A, Biomass Bioenerg., 2006, 30(2), 144-152; DOI:10.1016/j.biombioe.2005.11.006

27. Kang S, Jian-Chun J and Dan-dan C, Biomass Bioenerg., 2011, 35(8), 3643-3647; DOI:10.1016/j.biombioe.2011.05.007

28. Manoj Kumar Reddy P, Krushnamurthy K, Mahammadunnisa S K, Dayamani A and Subrahmanyam Ch, Int J Environ Sci Technol., 2015, 12(4), 1363-1372; DOI:10.1007/s13762-014-0506-2

29. Xiao-Mei S, Shu-Quan Z and Wen-Hui Z, J China Univ Mining Technol., 2008, 18, 261-265; DOI:10.1016/S1006-1266(08)60055-3

30. Wang S, Zhu Z H, Coomes A, Haghseresht F and Lu G Q, J Colloid Interf Sci., 2005, 284(2), 440-446; DOI:10.1016/j.jcis.2004.10.050

31. Jaramillo J, Alvarez P M and Gomez-Serrano V, Fuel Process Technol., 2010, 91(11), 1768-1775; DOI:10.1016/j.fuproc.2010.07.018

32. Bylina I V, Tong S and Jia C Q, J Therm Anal Calorim., 2009, 96(1), 91-98.

33. Tremblay G, Vastola F J and Walker P L, Carbon., 1978, 16(1), 35-39; DOI:10.1016/0008-6223(78)90113-6

34. Otake Y and Jenkins R G, Carbon., 1993, 31(1), 109-121; DOI:10.1016/00086223(93)90163-5

35. Ketcha J M, Dina D J D, Ngomo H M and Ndi N J, Am Chem Sci J., 2012, 2(4), 136160; DOI:10.9734/ACSJ/2012/1806

36. Poletto M, Zattera A J, Forte M M C and Santana R M C, Bioresour Technol., 2012, 109, 148-153; DOI:10.1016/j.biortech.2011.11.122

37. Acharya J, Sahu J N, Mohanty C R and Meikap B C, Chem Eng J., 2009, 149(1-3), 249-262; DOI:10.1016/j.cej.2008.10.029 